\title{
Nos limiares da literatura: histórias em quadrinhos, adaptações e outras artes
}

\author{
Déborah Alves Miranda ${ }^{1}$ \\ Josilene Pinheiro-Mariz ${ }^{2}$
}

\begin{abstract}
Resumo: As fronteiras entre a arte literária e outras artes é uma significante questão que vem sendo fonte de debates na academia, tanto no domínio das Letras, quanto no das Artes. Tal desconforto se dá diante de leituras de clássicos de obras literárias adaptadas para diversas outras mídias e, muito especialmente, das histórias em quadrinhos. Portanto, aqui discutimos sobre a leitura literária e a sua relação com as histórias em quadrinhos. Em se tratando de quadrinhos "nascidos" como obras literárias, o que dizer deles? O que caracteriza uma obra literária? Quais os limiares entre o que é e o que não é literatura? Eis algumas das ponderações que buscamos fazer ao longo deste trabalho, sob a luz das reflexões de Ferrier, (2009); Brait, (2010), Dürrenmatt (2013) e Pinheiro-Mariz (2013). Os resultados apontam para a necessidade de debates mais aprofundados e para uma imperativa reflexão sobre a relação entre língua e literatura.
\end{abstract}

Palavras-chave: literatura; artes; histórias em quadrinhos.

\section{Literature boundaries: comic books, adaptations and other arts}

\begin{abstract}
The boundaries between literary art and other sorts of arts areconsidered a significant issue that has been a source of debate in academy, both in the field of Modern Languages as well as in Arts. Such discomfort is due to the adaptation of classic literary works to several other media and, in particular, to comic books. Hence, we discuss here the relation between the literary classics and the comic books. What can be said about comics that were first "born" as literary works? What characterizes a literary work? What are the boundaries between what is and what is not literature? These are some of the considerations we present in this research based on the reflections of Ferrier (2009); Brait, (2010), Dürremmat (2013) and Pinheiro-Mariz (2013). The results show the need of further and deeper discussion on this issue and of an acute reflection on the relation between language and literature.
\end{abstract}

Keywords: literature; arts; comic books.

\section{Introdução}

É notória a evolução das discussões que envolvem a literatura em diálogo com outras artes. Brait (2010), nos apresenta excelentes reflexões a esse respeito ao apresentar

\footnotetext{
${ }^{1}$ É estudante de graduação no curso de Letras- Língua Portuguesa e Língua Francesa, da Unidade Acadêmica de Letras, da Universidade Federal de Campina Grande. Participa de projetos de ensino e de extensão, desenvolvendo sua pesquisa na perspectiva da não dissociação entre língua e literatura, enfocando o gênero História em Quadrinhos. e-mail: deborah.alves79@gmail.com

${ }^{2}$ Tem pós-doutorado em literatura francófona e didática do FLE pela Universidade Paris 8. Mestre e Doutora em estudos linguísticos literários e tradutológicos em francês pela Universidade de São Paulo. Professora do curso de Letras- Língua Portuguesa e Língua Francesa, da Unidade Acadêmica de Letras, da Universidade Federal de Campina Grande. Atua também na Pós-Graduação em Linguagem e Ensino da mesma universidade. e-mail: jsmariz22@ hotmail.com
} 
questionamentos ao leitor, como por exemplo: “Como se arranjam língua e literatura nas estantes da vida?” (BRAIT, 2010, p.11). Para essa especialista nos estudos bakhtinianos, a nossa vida é cercada pela arte, literatura e língua; então, como se dá essa organização na nossa vida? Evidentemente, encontramos em Jakobson (1969) uma possível resposta para essa compartimentalização entre a língua e a literatura, os dois grandes domínios do profissional de Letras. Para ele, se o especialista em literatura não abraça a área da linguística, e vice-versa, é falta de conhecimento da outra área. No dizer dele, é "incompetência". Duro? Sim! Bastante! Ora, se nos dois grandes domínios do profissional de Letras parece haver uma constante dissociação entre quem é de língua e quem é de literatura, como trazemos uma outra problemática, encaminhando as discussões no sentido de juntar ao debate, outras artes? Música, cinema, artes plásticas e muitas outras manifestações artísticas como histórias em quadrinhos (doravante HQ), também conhecido como um dos principais textos multimodais, não compreenderiam um conjunto que converge para uma relação entre uma linguagem verbal, visual e verbovisual, segundo a própria pesquisadora supracitada?

A HQ, obra que há uns cinquenta anos era apenas gibi, sem ter seu valor artístico reconhecido, tornou-se, a partir de estudos acadêmicos, um texto fonte de discussões que giram em torno do seu valor artístico e literário e há muito tempo vem conquistando o público não só infantil e adolescente, mas também o adulto. Entretanto, mesmo com essa expansão em termos de público alguns questionamentos sobre esse gênero ainda reverberam. Dentre esses está o fato de se acreditar que grandes obras literárias adaptadas para os quadrinhos perdem seu elemento principal e o seu aspecto polissêmico, que seriam os principais responsáveis por conduzir o leitor às múltiplas leituras.

Essa recusa em aceitar a HQ como uma obra literária é, muito provavelmente, devida ao fato de ela ser arquitetada sob um intercruzamento da linguagem icônica e da verbal, permitindo ao leitor a visualização do texto literário ao lado de imagens que o ilustram. Seja como bande dessinée; fumetti; banda desenhada; mangá; tebeos; comics, só para citar algumas das nominações dessa arte, ela reúne elementos linguísticos a dados icônicos e ganhou um público que cresce a cada dia e permanece fiel à essa arte. Entendemos que isso se dá diante da flexibilidade desse gênero, por se adequar às mais variadas culturas. É possível observar essa característica se considerarmos, por exemplo, que no ocidente, a HQ é estruturada e lida da esquerda para a direita; já no oriente é 
estruturada e lida da direita pra esquerda, adaptando-se ao sistema de normas das culturas e sociedades, ressaltando a sua flexibilidade.

Enquanto gênero autônomo e flexível, as HQ vem conquistando leitores desde o século XIX, com sua contextura que promove a interação ativa de elementos verbais e icônicos (ALMEIDA, 2001). Desde então, na cultura ocidental, elas estão ligadas à literatura infanto-juvenil, embora se saiba da existência de HQ direcionada para o público adulto. Todavia, há divergências quanto ao lugar que esse gênero deve ocupar dentro de uma dada categorização de gêneros literários ou artes visuais. Dessa forma, ao mesmo tempo em que para alguns estudiosos do assunto, é impossível colocá-la em um patamar de gênero literário, para outros, é muito possível ser classificada como gênero literário e ainda como suporte importante para a didatização do ensino de língua materna e estrangeira.

A respeito da linguagem da HQ, é possível defini-la como um:

[...] discurso tendencialmente narrativo em suporte fixo e portátil, implicando a interacção dinâmica de elementos do código linguístico e do código icónico, constituindo-se em objecto estético uno, autónomo e auto-suficiente, em que o todo seja mais do que a soma das partes. (ZINK, 1999, p. 20-21)

No Brasil, segundo a pesquisa Retratos da leitura no Brasil, $2^{a}$ edição, 2008 feita pelo Instituto Pró-livro (IPL), a leitura de HQ é realizada por leitores com idade entre 5 e 10 anos, o que segundo essa pesquisa corresponde a 36\% do público-leitor. Esse dado pode nos revelar que a utilização do suporte visual, presente na HQ faz com que o jovem leitor seja conduzido a construir sentidos que são constantemente implícitos no texto literário, promovendo, então, o caráter de fruição no ato da leitura. Com isso, é possível observarmos que a qualidade de uma obra literária não depende "[...] do seu formato, da sua extensão, do número de horas necessárias a sua leitura, mas daquilo que ela é capaz de propor e suscitar enquanto objeto de leitura" (ALMEIDA, 2001, p.115).

Diante dessas circunspecções, entendemos que a relevância deste artigo reside no fato de discutir questões indispensáveis para o estudante e o profissional de Letras, quando dá enfoque à adaptação de obras literárias, em um primeiro momento de sua constituição. Na sequência, refletimos, ainda que moderadamente, sobre a própria literatura em HQ, ressaltando os estudos de Ferrier (2009) e Dürenmatt (2013) concernentes ao debate sobre a literatura infanto-juvenil, HQ e outros textos "literários"; evidentemente, iremos afunilar nossa perspectiva para a questão da literatura em HQ. Ao longo de todo esse debate, apoiar-nos-emos nas pesquisas de Brait (2010) que ratifica a 
importância das linguagens associadas à literatura e em Pinheiro-Mariz (2013), no que diz respeito à necessidade da não dissociação entre a língua e literatura no âmbito do ensino. Para concluir as nossas exposições sobre os limiares da literatura e as artes, ressaltamos a adaptação de obras literárias, em quadrinhos, como um possível motivador para a leitura literária.

\section{HQ entre a arte e as artes: literatura e adaptações}

Considerada nona arte, a HQ é uma narrativa feita a partir da sucessão de quadrinhos que em conjunto com o verbal formam a narrativa conhecida como gráfica. Os quadrinhos, por muito tempo, foram considerados um tipo de leitura inferior, por apoiar sua narrativa nas imagens sendo até acusados de mutilar a imaginação do leitor.

Com a predominância das imagens na HQ, ela ganhou um status, por assim dizer, negativo, de obra menor; mas hoje, esse status vem mudando e, aos poucos, ela tem conquistado seu lugar em meio ao mundo literário. O fato é que possuir imagens na HQ não a desmerece, pelo contrário, torna-a ainda mais complexa, ler imagens e associá-las ao texto verbal e em sequência é uma tarefa não, exatamente, fácil e que exige sensibilidade do leitor. A imagem apresenta benefícios, segundo Santaella (2012):

Percebemos os elementos de uma imagem de forma simultânea, tudo ao mesmo tempo, mesmo que nossa atenção não se dirija imediatamente a todos os detalhes com igual intensidade. O texto escrito, por outro lado, é produzido de maneira linear, uma palavra depois da outra, e recebido de forma sucessiva, como a língua falada. (SANTAELLA, op. cit., p.107)

Não fosse a afirmativa da especialista em semiótica, o fato é que ainda hoje, esses questionamentos vem instigando profissionais da área das Letras à procurar uma resposta satisfatória para a questão que discute se a história em quadrinhos é um gênero literário ou "simplesmente"” arte plástica. As HQ se encontram, atualmente, em dois extremos; de um lado, há reservas que não permitem ao leitor ver nelas, a carga de conotação própria da literatura; nesse sentido, alguns não a consideram uma obra literária. Já para outros, a HQ constituem-se no inverso, isto é: tem características evidentes de uma obra literária. Isso é visto, por exemplo, em alguns livros didáticos que consideram esse gênero como

\footnotetext{
${ }^{3}$ Esse "simplesmente", destacado, tem uma relação direta com o fato de que, tradicionalmente, a literatura é vista como uma arte inalcançável, feita por e para poucos e iluminados; portanto, canonizada, sendo o inverso da HQ que pode ser lida até mesmo por incautos.
} 
um elemento favorável para a formação de jovens leitores, em particular, na literatura infantil. (MIRANDA; PINHEIRO-MARIZ, 2012).

No âmbito da história em quadrinhos, o código icônico contribui para constituição do contexto e, a formação do contexto, por sua vez, leva o leitor a construir os sentidos. Esses sentidos são arquitetados a partir das representações de elementos icônicos presentes nos quadrinhos e da sua correlação com elementos exteriores a eles. As imagens que compõem os quadrinhos não estão ali por acaso elas constituem um todo significativo, uma vez que a imagem não é separada do todo, coeso, que nos transmite algo, remetendonos a elementos transpostos do mundo real, provocando o imaginário do leitor; logo, esse efeito de mimesis é um dos elementos que faz da HQ uma obra literária. Na construção desse todo significativo, o contexto tem um papel fundamentalmente importante nessa promoção.

Um dos primeiros estudiosos, da nossa época, a se debruçar de modo mais sistemático e acadêmico sobre os quadrinhos, foi Luíz Antonio Cagnin, que desde os anos de mil novecentos e setenta vem trazendo essa discussão para academia universitária no Brasil. No que concerne ao contexto no âmbito dos quadrinhos, Cagnin (1975), o depreende em 3 categorias principais; o contexto intra-icônico; o contexto intericônicocontexto situacional, contexto global. $\mathrm{O}$ autor define o contexto intra-icônico como o das relações entre as imagens e os diferentes elementos que a constituem. Já o contexto intericônico se caracteriza pela relação entre as imagens de forma sequenciada. Por fim, o contexto extra-icônico é definido como sendo a imagem e sua associação com elementos de natureza diversa, o que envolve os aspectos temporais de produção (tempo: quando e espaço: onde) e esse contexto intericônico pode ser detalhado em contexto situacional, agregando o conjunto de elementos comuns ao emissor e ao receptor que, no ato de comunicação, são permutados; e, no contexto global todas as representações culturais e espaço-temporais são levados em consideração.

Se estabelecermos uma diferença entre o código linguístico e o icônico, veremos que a decodificação da unidade linguística vai da parte para o todo, ao passo que a decodificação da unidade icônica vai do todo para as partes (CAGNIN, 1975, p. 52). Esse importante pesquisador também destaca que se considerarmos as formas variantes de traços nos desenhos nos quadrinhos que se caracterizam por serem manuais, veremos que eles influenciam diretamente na leitura, implicando em diferentes formas de ler uma mesma história. Nesse aspecto também observamos que a HQ, por si só, assemelha-se à 
obra literária, pois o conhecimento de mundo do leitor pode dar vieses diferentes para a interpretação do texto.

Por não apresentar elementos da escrita formal, representando somente a fala dos personagens e os sons do ambiente (com o uso das onomatopeias), essa arte foi sendo considerada não como literária, mas como um gênero "marginal". Com isso podemos perceber que a crença popular de que "a fala é a desconstrução dos moldes formais de escrita" afeta de forma incisiva esse gênero. Além disso, a linguagem icônica se sobressai como elemento inovador, porém, essa predominância do icônico nas HQ, conforme nos diz Eisner (2008, p.20) "sempre provocou resistência à sua aceitação como leitura séria. Às vezes, alguns críticos acusam os quadrinhos de inibirem a imaginação”.

O fato é que se trata, aqui, de duas artes distintas: a arte gráfica e a literária. Por essa razão, talvez ainda se tenha certo "cuidado" em ler um texto literário adaptado para os quadrinhos. É Ramos e Vergueiro (2009) que melhor discutem essa questão, ressaltando o valor da obra literária, sem preterir a arte gráfica; afinal, não é nosso intento julgar essa ou aquela arte, uma vez que as percebemos em valores peculiares. No entanto, se pensarmos na perspectiva de Brait (2010), entenderemos o porquê da necessidade de se trabalhar com leitores, iniciantes, obras adaptadas em quadrinhos ou em outro formato.

Ora, se no âmbito das leituras literárias, de um modo geral, já não se vê a HQ com interesse canônico, posto ser ela um texto, inicialmente, endereçado às crianças, o que dizer dos clássicos adaptados de obras como Tartuffe, de Molière ou A Divina Comédia, de Dante, para HQ? Considerando-se esses dois exemplos de adaptações, podemos assegurar que, sob a nossa ótica, elas não perderam o seu elemento principal de enlevo literário. Isto se dá porque o valor estético está presente no texto, levando o leitor a associar o texto à imagem, induzindo-o a construir vários sentidos a partir disso. E no caso particular da Divina Comédia (2012), da editora Petrópolis, vale ressaltar que conta também com a tradução do grande poeta brasileiro e iniciador do concretismo, Haroldo de Campos (19.08.1929-16.08.2003), elemento que destaca o valor estético da HQ da obra do famoso florentino.

Neste caso, temos dois eixos a discutir. O primeiro, Tartuffe, nos aponta para uma adaptação que visa à leitura de jovens leitores em uma língua estrangeira (jovens na aprendizagem da língua). O segundo é uma tradução da obra-prima de Dante Alighieri, o grande poeta italiano dos fins da Idade Média, refletindo, nesse último caso, temos uma tradução adaptada. Mas, o importante é ratificar que clássicos adaptados para quadrinhos 
já correspondem a um importante quantitativo, visto que o público recebe bem essas obras. Portanto, subentende-se que a relação qualidade e quantidade andam juntas em prol da leitura de clássicos da literatura.

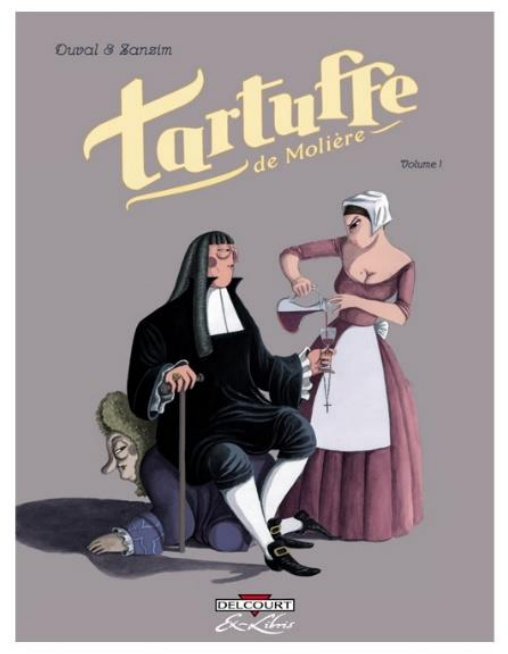

Figura 1: Capa de Tartuffe, de Molière, adaptada para HQ

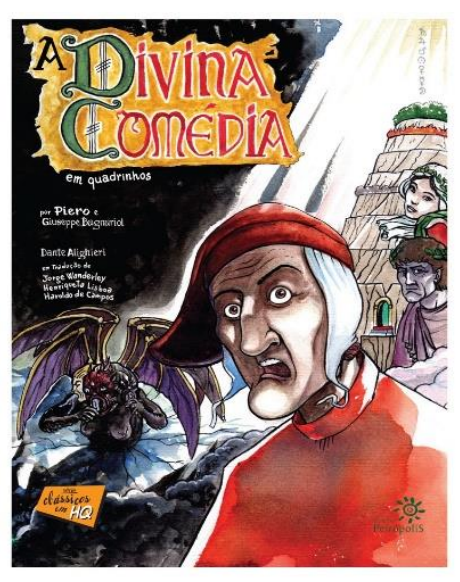

Figura 3: Capa de A Divina Comédia, de Dante Alighieri,

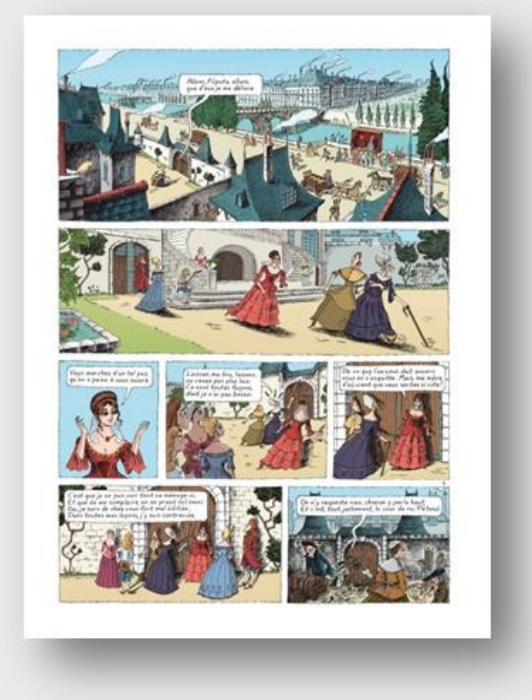

Figura 2: Imagens de Tartuffe, de Molière, adaptada para HQ

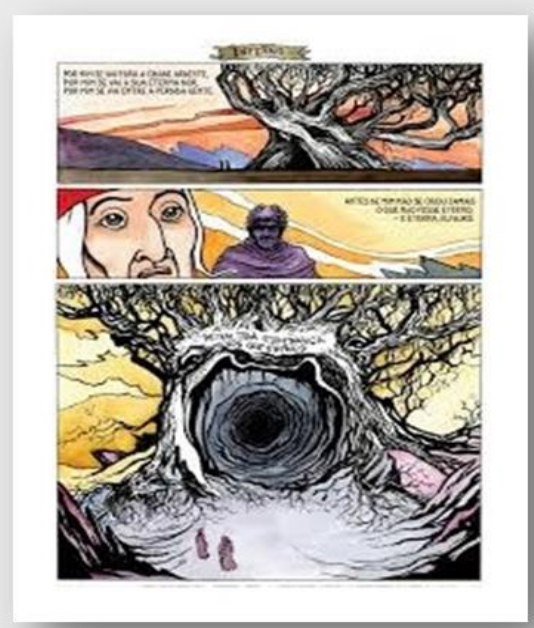

Figura 4: Imagens de A Divina Comédia, de Dante Alighieri em

É necessário levar em conta que, de fato, algumas adaptações não possuem uma boa qualidade, outras não são fieis às obras originais e, ainda, outras são tão fiéis que parecem apenas ter havido remoção total do texto original e transferência para os balões de fala. Isso teria feito com que as adaptações obtivessem o status de "obra banal”. Fazse necessário, portanto, procurar um ponto de equilíbrio entre o texto original e os 
elementos indispensáveis a uma adaptação. É significativo ressaltar que texto e imagem são meios diferentes de comunicação e que mesmo sendo assim não existe a perda de literariedade visto que os quadrinhos não desconstroem a obra, apenas utilizam a estrutura do texto literário como o enredo e os fatos que circundam a obra, transferindo-os para um novo suporte.

\section{Linguagens e a arte literária no ensino}

Quando uma obra é adaptada para os quadrinhos, geralmente, o que se observa é que o número de páginas é reduzido e que nem todo o enredo da obra original consta no novo texto, isso acontece porque não é possível colocar todo o texto da narrativa literária nos quadrinhos, pois isso acarretaria problemas na sequência dos quadrinhos e, portanto, na sequência da narrativa. Então, a narrativa gráfica sequencial é dinâmica e direta não precisa de detalhamento no texto verbal como na obra original visto que a narrativa sequencial possui o recurso das imagens que é o elemento responsável por essa descrição (SELBACH, 2010). Dito de outra forma, na maioria das vezes, a adaptação que pode ser considerada como um bom texto, mesmo que não tenha o texto integral, é completada pelas imagens, finalizando, desse modo, a junção entre o verbal e o não verbal.

Sabemos que assim como acontece com as traduções, as adaptações também apresentam ressalvas, dependendo, evidentemente, de quem a faz; no entanto, uma obra literária adaptada aos quadrinhos não deixa de lado seus elementos principais quando da sua construção. A obra adaptada permite que o aprendiz leia, considerando seus marcos históricos, o que faz com que ele viaje no tempo em busca de sentidos que estão implícitos nos textos.

Considerando-se que as adaptações de obras literárias para os quadrinhos configuram-se como uma forte discussão, alguns críticos não percebem em uma obra adaptada para os quadrinhos a literariedade. Isso porque, a HQ não é vista como uma leitura complexa, mas como uma leitura fácil por possuir a predominância de imagens em sua composição o que extinguiria a imaginação do leitor.

Acreditamos que uma das principais razões que, ao longo de muitos anos, manteve a HQ longe da academia ou de qualquer outro lugar considerado sério, como as salas de aula é essa ideia de sub arte ou algo não tão sério. Os pais e, até mesmo, os professores 
resistiram a esse tipo de forma de expressão por achar que ela afastaria os jovens de leituras "mais profundas" como afirma Vergueiro, (2004):

Pais e mestres desconfiavam das aventuras fantasiosas das páginas multicoloridas das HQs, supondo que elas poderiam afastar crianças e jovens de leituras "mais profundas", desviando-os assim de um amadurecimento "sadio e responsável". Daí, a entrada dos quadrinhos em sala de aula encontrou severas restrições, acabando por serem banidos, muitas vezes de forma até violenta, do ambiente escolar. Aos poucos, tais restrições foram atenuadas e extinguidas, mas não de forma tranquila, sendo na verdade resultado de uma longa e árdua jornada. (VERGUEIRO, op. cit, p. 8).

Observamos, portanto, que ainda hoje essa jornada longa e árdua. Quando em um mesmo discurso se articula HQ e ensino, aos ouvidos dos críticos literários isso soa como algo não conectado, que não pode se misturar, evidentemente, pelo valor canônico da obra literária. Mesmo levando-se em conta que as HQ estão presentes nos capítulos dos manuais de língua portuguesa e também os manuais de língua estrangeira ainda se vê hoje uma resistência ao uso dessa arte que é também literária. Contudo, tem-se visto hoje alguns avanços quanto à concepção do que é uma história em quadrinhos e quais suas contribuições em sala de aula de língua materna e estrangeira. Têm-se observado, no âmbito da didática de línguas estrangeiras que, por exemplo, a $\mathrm{BD}^{4}$ estimula os aprendizes do FLE a aprimorarem as habilidades de expressão oral e escrita.

No livro Parler et écrire avec la bande dessinée, de Rollet (1978), são elencados alguns pontos nos quais a HQ pode contribuir no processo de ensino/aprendizagem de língua. Dentre os pontos elencados pelo autor está o fato de desenvolver "progressivamente suas competências de comunicação em língua estrangeira levando-os a tomar a palavra, a formular uma opinião, a argumentar e debater a partir de um suporte visual original e motivador"5. Exatamente por seu caráter original e inovador, as imagens utilizadas na HQ aproximam o leitor de um ponto de experiência corriqueira, dando voz, através da imagem, aos fatos da vida real.

Ainda no tocante ao ensino de língua estrangeira, mas, agora, para crianças, observa-se que a utilização de imagens se faz totalmente necessária. Thibault-Laulan (1971, apud, CAGNIN, 1975) discorreu sobre a linguagem da imagem e diz que "seria

\footnotetext{
${ }^{4}$ Do francês, bande dessinée

${ }^{5}$ Développer progressivement leur compétence de communication en langue étrangère en les amenant à prende la parole, à formuler une opinion, à argumenter et débattre à partir d'un support visuel original et motivant. (ROLLET, op. cit., p. 03)
} 
conveniente ensinar primeiramente às crianças a arte de interrogar as imagens, antes que se utilize das imagens para lhes aumentar conhecimento". Quando uma criança ouve ou lê uma história ela cria várias representações icônicas na sua imaginação, tentando aproximar a história que ela ouve ou lê à uma imagem, a fim de tornar a história, no seu todo como um texto mais coeso.

A HQ não é mais do que a concretização disso, a imagem em conexão com o texto verbal unifica a narrativa e seus sentidos e isso não extingue, de forma nenhuma, a utilização do imaginário da criança; pelo contrário, estimula-a a criar outros sentidos a partir da representação imagética posta nos quadrinhos. É olhar no desenho do outro uma forma diferente de leitura de uma mesma história e procurar pontos de convergência e divergência entre a sua visão, enquanto leitor, e a leitura do outro enquanto autor e /ou design gráfico.

\subsection{Adaptação da obra Le Petit Prince}

Se considerarmos a adaptação do romance Le Petit Prince, de Antoine de SaintExupéry e a compararmos à obra original, veremos que muito pouco foi perdido, se é que aconteceu alguma perda ao longo do processo de adaptação. Isto se dá porque a função poética ainda permeia o texto, levando o leitor a associar o texto à imagem, induzindo-o a construir vários sentidos a partir disso. 

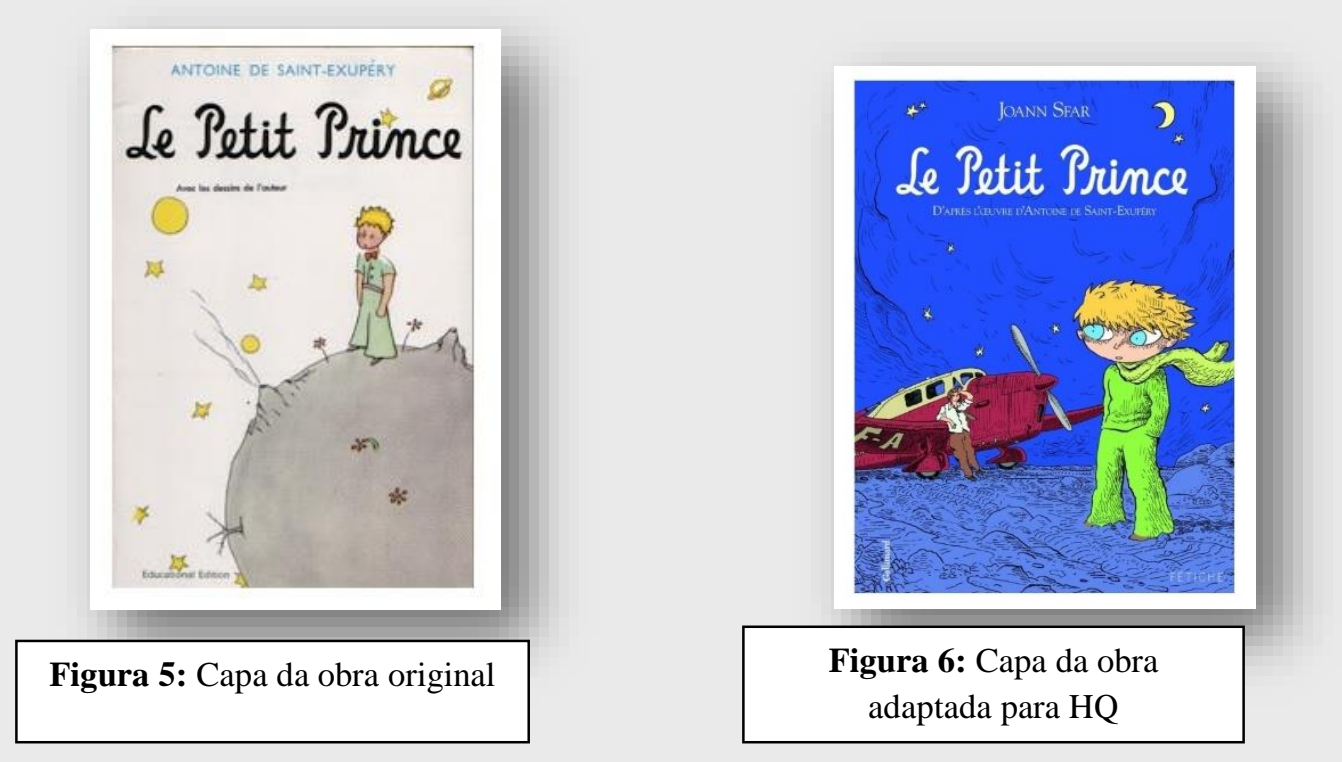

Cotejando as duas obras, identificamos que não há grandes diferenças entre as duas obras mesmo que evidentemente sejam suportes diferentes. Desde a capa de ambos, verificamos que não há mudança de perspectiva, pois enquanto na obra escrita e ilustrada por Exupéry, vê-se o planeta, sinalizando a viagem do personagem central por vários planetas em busca de respostas às suas inúmeras perguntas, na adaptação, é também a viagem que se percebe ao ser ilustrada por um avião. Nesse caso, a presença do personagem aviador dá enfoque aos diálogos que configuram-se no cerne da obra: os diálogos constatando a busca.

De uma maneira geral, os elementos que foram retirados da obra original foram os diálogos do Pequeno Príncipe com os personagens. Essa HQ se caracteriza por seu aspecto dialogal e na adaptação esse elemento importante foi transferido da obra original para os quadrinhos. As outras partes da obra original não foram transferidas visto que as imagens contidas nos quadrinhos já possuem a caracteristica de descrição do ambiente e dos personagens. O que foi retirado da obra original para os quadrinhos foram os seus elementos principais já mencionados anteriormente, como os personagens e as cirscuntâncias que envolvem a narrativa, como o espaço.

Se considerarmos a arte gráfica, como a questão do traço do desenho veremos que na obra original os desenhos foram feitos pelo próprio autor do livro, enquanto na adaptação para os quadrinhos os desenhos foram feitos por um tradutor gráfico. Porém, constatamos que isso não afeta a qualidade da adaptação, só o que apresenta mudança é o traço do desenho mas o cenário e os personagens são os mesmos propostos por Saint- 
Exupéry. Portanto, não há mudança significativa quanto aos desenhos, todavia, o traço tem uma diferença bem mais marcante que se dá, muito provavelemente por cuidado em atualizar a obra já que a adaptação foi feita mais de cinquenta anos após a publicação do romance original.

Dessa forma, vemos que os traços dos desenhos bem como a seleção do texto dos quadrinhos é um processo importante no momento da adaptação. A adaptação de uma obra literária para os quadrinhos não é uma forma de dar menos status à literatura, mas, sim, uma forma de mostrar que o texto literário permanece com o seu elemento principal, a literariedade, mesmo quando associado a imagens em uma narrativa gráfica sequencial como é a história em quadrinhos. E ainda se considerarmos os aspectos envolvidos no ato de leitura, veremos que a imagem em conexão com o texto nos quadrinhos adiciona um caráter de fruição à leitura.

Assim, cabe-nos ressaltar que se é necessário encontrar caminhos para que a literatura seja levada aos leitores nas mais diversas faixas etárias, tanto em língua materna, quanto na estrangeira. Assim, a proposta de oferecer, desde cedo, aos aprendizes a HQ adaptados de obras canônicas constitui-se em um viés especial, sobretudo quando se trata do ensino de LE para crianças. Vale ressaltar ainda que com isso não queremos dizer que a obra literária em seu formato original não seja atrativa, os quadrinhos são apenas uma nova forma de ler o texto literário. Com isso, concordamos com a afirmação de Figueiredo (2010):

[...] a HQ assume-se como um recurso motivador para os alunos, uma vez que alia imagens ao texto, apresenta-se de forma colorida e com textos curtos. A relação icónico-verbal, para além de promover a motivação, também pode auxiliar o aluno a melhor compreender 0 texto que lê e, simultaneamente, ajuda à sua interpretação, enquanto estimula a sua imaginação. (FIGUEIREDO, op. cit., p.20)

Esse seria, portanto, um dos principais elementos que nos fazem ver a HQ como um texto motivador da leitura literária, posto que essa junção, como já sinaliza Santaella (op. cit.) do verbal com o não verbal constituem-se em um importante elemento que agrega valores à obra e, sob o nosso prisma, pode ser a porta de entrada para sensibilizar o leitor iniciante a ler textos literários diversos, desde os considerados mais simples, até os de maior complexidade. Em vez de mutilar a imaginação, entendemos que leitura desse gênero pode estimular o imaginário do leitor, incitando-o a conhecer mais sobre a obra e conduzindo-o a uma formação leitora que o instigue à ler, puramente. 


\section{Algumas conclusões}

Após estas reflexões, seria possível afirmar que a complexidade da questão é tênue, pois, lidamos com elementos que demandam uma delicada ponderação, uma vez que tratamos de textos polissêmicos e de arte. Então, poderíamos fortalecer a ideia que as HQ podem ser constituídas em auxílio no processo de formação de jovens leitores de obras literárias, sobretudo, quando se fala do ponto de vista do ensino de uma língua estrangeira.

No momento de concluir, lembramo-nos que a leitura de adaptações de obras literárias para os quadrinhos constitui-se em uma problemática que ainda necessita de muito debate, pois ponderar se uma HQ adaptada continua sendo considerada literatura incita cogitações indispensáveis para melhor formação leitora de aprendizes de FLE, desde o início da aprendizagem. Ou ainda se uma obra concebida como HQ pode ser lida como literária em toda a sua completude continua a ser um ponto de debate que gera divergências, mas que pode suscitar convergência se pensarmos essa leitura como uma sensibilização, como um início à leitura da literatura. Considere-se que o recurso icônico da HQ dá um caráter inovador a esse gênero, mostrando que é possível a leitura de uma imagem, bem como a atribuição de sentidos a ela mesmo que não possua texto verbal. As adaptações de grandes obras literárias se configuram como uma nova forma de olhar para o texto literário, por lhe dar um novo suporte, o imagético; e, isso não deve ser visto como mutilação.

Portanto, ao voltarmos à Brait (2010), pensando na relação do homem com as artes, é importante que não se perca de vista que os limiares são tênues, a língua e a literatura estão/são próximas e as manifestações artísticas que são compostas pela língua, resultando em literatura como uma excelente escola lexical, são a essência do homem, pois nas prateleiras da vida, no dizer da pesquisadora, só é necessário organizar e não, simplesmente, separar.

No âmbito da didática das línguas, constatamos que as HQ são importantes como suporte pedagógico para o ensino de uma LE, pois desenvolvem as competências comunicativas dos aprendizes. No nosso caso, em especial, da aprendizagem de FLE para crianças instigou-as a desenvolver um apreço pela leitura e, consequentemente, pelo texto literário.

\section{Referências}


ALMEIDA, F. A. Arquitetura da história em quadrinhos Vozes e linguagens. Linguagem \& Ensino, São Paulo, v. 4, n., p.113-140, 2001.

BOUTHIER, C. et al. Mille ans de littérature française. Paris: Nathan, 2003.

CAGNIN, L. A. Os quadrinhos. São Paulo: Ática, 1975.

DÜRRENMATT, J. Bande dessinée et littérature. Paris: Classiques Garnier, 2013.

EISNER, W. Narrativas Gráficas: princípios e práticas da lenda dos quadrinhos. 2. ed. São Paulo: Devir, 2008.

EISNER, W. Quadrinhos e Arte Sequencial: princípios e práticas do lendário cartunista. 2. ed. São Paulo: WMF Martins Fontes, 2010.

FERRIER, B. Tout n'est pas littérature: la littérature à l'épreuve des romans pour la jeunesse. Rennes: PUR, 2009

FIGUEIREDO, M. M. F. A banda desenhada como recurso didáctico nas aulas de Língua Materna e de Língua Estrangeira. 2010. 64 f. Dissertação (Mestrado) Faculdade de Letras Universidade do Porto, Porto, 2010. Cap. 3.

JAKOBSON, R. Linguística e comunicação. Tradução de Isidoro Blikstein e José Paulo Paes. São Paulo: Cultrix/ EDUSP, 1969.

MIRANDA, D. A; PINHEIRO-MARIZ, J. La bande dessinée em manuais de literatura francesa para o ensino de FLE: um gênero literário? In: Colóquio Nacional 15 de outubro, 1, 2012, Campina Grande. Anais. Campina Grande: Revista Letras Raras, 2012. p. 356365 .

PINHEIRO-MARIZ, J. (org.) Em busca do prazer do texto literário em aula de línguas. São Paulo : Paco Editorial, 2013.

ROLLET, G. Parler et écrire avec la bande dessinée. Paris: Hachette, 1978.

SANTAELLA, L. Leitura de imagens. São Paulo: Melhoramento, 2012.

SELBACH, L. C. A Cor que veio do Espaço: Uma adaptação literária para as histórias em quadrinho. 2010. 252 f. Monografia (TCC) - Departamento de Design e Expressão Gráfica, Universidade Federal do Rio Grande do Sul, Porto Alegre, 2010.

VERGUEIRO, W. HQ e ensino. In: RAMOS, Paulo; VERGUEIRO, Waldomiro; RAMA, Ângela. Como usar as histórias em quadrinhos na sala de aula. São Paulo: Contexto, 2004. Cap. 1, p. 07-29.

ZINK, R. Literatura Gráfica? Oeiras: Celta, 1999 